Portland State University

PDXScholar

$10-2016$

\title{
Predicting Positive Education Outcomes for Emerging Adults in Mental Health Systems of Care
}

\author{
Eileen M. Brennan \\ Portland State University \\ Peggy Nygren \\ Portland State University, peggynygren@gmail.com \\ Robert L. Stephens \\ Adrienne Croskey
}

Follow this and additional works at: https://pdxscholar.library.pdx.edu/socwork_fac

Part of the Educational Assessment, Evaluation, and Research Commons, and the Social Work Commons

Let us know how access to this document benefits you.

\section{Citation Details}

Brennan, E. M., Nygren, P., Stephens, R. L., \& Croskey, A. (2015) Predicting Positive Education Outcomes for Emerging Adults in Mental Health Systems of Care.

This Post-Print is brought to you for free and open access. It has been accepted for inclusion in School of Social Work Faculty Publications and Presentations by an authorized administrator of PDXScholar. Please contact us if we can make this document more accessible: pdxscholar@pdx.edu. 


\title{
Predicting Positive Education Outcomes for Emerging Adults in Mental Health Systems of Care
}

\author{
Eileen M. Brennan, Peggy Nygren, \\ Robert L. Stephens, \& Adrienne Croskey
}

\begin{abstract}
Emerging adults who receive services based on positive youth development models have shown an ability to shape their own life course to achieve positive goals. This paper reports secondary data analysis from the Longitudinal Child and Family Outcome Study including 248 culturally-diverse youth ages 17 through 22 receiving mental health services in systems of care. After 12 months of services, school performance was positively related to youth ratings of school functioning, and service participation and satisfaction. Regression analysis revealed ratings of young peoples' perceptions of school functioning and their experience in services added to the significant prediction of satisfactory school performance, even controlling for sex and attendance. Finally, in addition to expected predictors, participation in planning their own services significantly predicted enrollment in higher education for those who finished high school. Findings suggest that programs and practices based on positive youth development approaches can improve educational outcomes for emerging adults.
\end{abstract}

\section{Introduction}

The current study takes a positive development approach to examine education outcomes for emerging adults engaged in mental health services. Young people with higher levels of educational attainment find themselves on pathways to satisfying careers and better employment as adults. ${ }^{1,2}$ Such positive outcomes for emerging adults have been linked to their ability to shape their own life course through the development of expectations for a positive future, and the exercise of personal agency ${ }^{3}$ Schwartz et al. ${ }^{4}$ have defined agency as "a sense of responsibility for one's life course, the belief that one is in control of one's decisions and is responsible for their outcomes, and the confidence that one will be able to overcome obstacles" (p. 207). Practices and programs for emerging adults that promote their positive development focus on supporting young people as they strive to take charge of their own lives and navigate the difficult waters they may encounter on their way to adulthood. ${ }^{5-9}$ Positive youth development approaches are frequently based on a relational developmental systems framework in that the young person develops within a context of relationships with others who encourage movement toward positive outcomes. ${ }^{8,9}$

Many emerging adults are involved in service systems that have been evolving to meet their particular needs as young people with serious mental health conditions (SMHC), promote their empowerment and personal agency, and foster their recovery and even thriving. ${ }^{9}$ When affected by serious mental health conditions, emerging adults may 
experience challenging symptoms that limit their ability to focus on academic work, to deal with the pressures of looming deadlines and competing tasks, and to successfully interact with educators and peers. ${ }^{10}$ These challenges may contribute to the discouraging education outcomes noted in national studies of young people receiving special education services because of their mental health and academic difficulties. ${ }^{11-13}$ Despite these challenges and the stigmatizing beliefs held by some school personnel and peers, ${ }^{14,15}$ many emerging adults who have received developmentally-appropriate services for mental health difficulties graduate from secondary education and go on to higher education and satisfying careers. ${ }^{12,16,17}$

The present investigation involves secondary analysis of data regarding emerging adults from the Longitudinal Child and Family Outcome Study (LCFOS) ${ }_{18}^{18}$ which is part of the national evaluation of the Comprehensive Community Mental Health Services for Children and their Families Program, also referred to as the Children's Mental Health Initiative (CMHI). The CMHI database provides a unique opportunity to examine changes in domains affecting young people over time, as they participate in services provided through comprehensive service systems, and they and their families participate in a multilevel, multicomponent national evaluation. ${ }^{19}$ Using a positive developmental lens, the next sections examine two strands of literature: education outcomes of young people with mental health difficulties, and potential predictors of positive outcomes in education for these emerging adults. With the literature as a guide to potential pathways to prediction of positive outcomes, the resulting specific aim and hypotheses of the study are then set forth.

\section{Education Outcomes for Young People with Mental Health Disorders}

Over the past two decades, national surveys have collected data on the educational outcomes of young people receiving special education services in the USA. ${ }^{11-13}$ Reports published on data collected in the 1990s through the National Longitudinal Transition Study (NLTS) included particularly discouraging outcomes for high school students with the designation of emotional disturbance (ED). Students with ED were less likely than other students receiving special education services or their peers in general education to graduate from high school $(47.4 \% \mathrm{ED}$, $76.0 \%$ peers) and to go on to postsecondary education (18.0\% ED, $54.0 \%$ peers). The most recent National Longitudinal Transition Study (NLTS2) demonstrated that although students who had a designation of ED were as likely as their peers in the general population to complete secondary schools (78.1\%), they were much less likely to enroll in postsecondary education (34.7\% ED, $62.6 \%$ peer group). ${ }^{12,13,20}$

The national data set used in this study represents young people engaged in mental health treatment in federally-funded systems of care (SOC), and allows an examination of outcomes for emerging adults who are not necessarily receiving supportive services in their school setting through special education. Emerging adults receiving services in SOC share similarities with emerging adults described in other studies with regard to their clinical and functional characteristics, living situations, and service needs. ${ }^{21}$ These youth most frequently received individual therapy, case management, and medication treatment/monitoring. Appropriately, they were also more likely to receive transition and independent living services than younger individuals served in SOC. At intake into SOC, they were at the age when many young people are gearing up to complete their secondary education. The current study includes a culturally-diverse group of young people being served in SOC designed for children and youth, and explores key variables at intake and 6 and 12 months to determine predictors of their education outcomes.

The first outcome examined in the study is school performance, as measured by the grades the young people in SOC obtained in their educational settings. When young people are attaining at least satisfactory grades in school, they are more likely to complete high school, and to engage in post-secondary education and career training programs. ${ }^{22-25}$ The second major outcome is completion of secondary education through either graduating from high school or passing a General Education Development (GED) test. Finally engagement in 
higher education is studied as the third major outcome. Successful performance in higher education settings is particularly difficult for young people with SMHC, and has been linked to the type of mental health difficulty they experience, their use of services, and organizational supports. ${ }^{26}$

What will predict positive education outcomes for these young people? Aligned with a positive development framework, four sets of potential predictors of education success are proposed: selfreported school functioning, participation in services, experiencing culturally responsive services, and satisfaction with services. Finally, the literature examining school attendance patterns and possible control variables will be considered.

\section{Predictors of Positive Education Outcomes}

School functioning. Using the lens of positive development to locate predictors of success, young people's belief in their own competence to engage in educational activities seems key. ${ }^{7,27,28}$ When youth and their families report better school functioning as part of an overall strengths assessment, ${ }^{29,30}$ young people may be more likely to perform well academically and complete secondary school and higher education. In a study of 365 younger children (mean age 12.6 years) enrolled in SOC, Anderson ${ }^{31}$ found that scores on the Behavioral and Emotional Rating Scale (BERS), a strengths-based instrument which includes items on school functioning, significantly predicted school performance, measured as a combination of grades, attendance, and discipline. Additionally in a study conducted by Brown et al., ${ }^{32}$ adolescent involvement with the juvenile justice system exhibited associations with school functioning scores, as measured by the BERS, and school performance measures.

Participation in services. One of the hallmarks of SOC is that services are to be tailored to the needs and strengths of young people and their families. ${ }^{33,34}$ Service providers support self-determination in young people by helping them to develop the ability and motivation to guide their own life course toward goals that are personally meaningful for them and to gather the resources they need to reach those goals. ${ }^{35,36}$ In the context of SOC, service providers can help promote self-determination in young people by fostering their genuine participation in services. Emerging adults can be encouraged to choose their own treatment goals and services, and to actively participate in services. The levels of youth-reported participation in services, as an indicator of self-determination, may predict their ability to achieve success in education. ${ }^{37}$

Culturally responsive services. In the United States, studies have established that disparities exist in the rates of high school completion for young people of different racial and ethnic backgrounds. ${ }^{38}$ Youth from African American, Hispanic, and Native American cultural backgrounds are more likely to leave school without a diploma, and not to pursue higher education, in comparison to White or Asian American peers. ${ }^{39,40}$ Services delivered in SOC need to be culturally responsive to build trusting, supportive relationships with young people and their families $^{41,42}$ and to counteract the negative forces pushing or pulling young people from diverse cultural backgrounds to leave or disengage from treatment and educational settings. ${ }^{43,44}$ Diverse young people receiving services in SOC that are provided with greater cultural sensitivity may be more ready to engage in educational activities due to improved behavioral strengths gained from services that are compatible with their cultural heritage and family preferences. ${ }^{45}$ Young people's ratings of the cultural sensitivity of their services may be linked to their educational outcomes.

Youth satisfaction with services. Little research has examined the relationship between service use, service satisfaction, and clinical and functional outcomes when young people have complex needs. A recent study by Ungar et al., ${ }^{46}$ including 497 young people between 13 and 21 years of age who were involved in multiple service systems, showed that satisfaction with their services was significantly related to resilience, which included engagement with education and seeing education as relevant. ${ }^{46}$ The researchers also found that resilience was a mediator between service satisfaction and functional outcomes, including school enrollment, attendance, and progress. ${ }^{46}$ In the current study, two variables assessing quality of services are proposed as 
possible predictors of education outcomes. Young people rating themselves as having better treatment outcomes and having greater service satisfaction may be more likely to perform well in school and engage in higher education.

School attendance and control variables. Consistent school attendance has been linked to school performance and completion of secondary education for the general population; frequent $a b-$ sences have been strongly associated with poorer grades and disengagement from education. . $^{23-25,47,48}$ Studies of young people receiving mental health treatment also found similar results: school attendance was a predictor of education outcomes. ${ }^{49,50}$ Other variables known to be related to academic performance, school completion, and engagement in post-secondary education include age, sex, race, and mental health functioning. ${ }^{11,51,52}$

\section{Research Questions}

The aim of the current research was to examine the relationship between youth experiences in mental health services, school functioning, school attendance, and the outcomes of school performance, completion of secondary education, and enrollment in higher education. The study examines two major research hypotheses: (1) Over and above demographic characteristics of the young people, school attendance and self-ratings of school functioning will improve prediction of school performance; furthermore, their ratings of service participation, service satisfaction, service outcomes, and cultural sensitivity of services, will add to the prediction of better school performance. (2) After taking demographic characteristics into account, ratings of school functioning, participation in services, cultural sensitivity of services, and service satisfaction will predict completion of secondary education and engagement in higher education; school attendance and school performance will add to the prediction of engagement in higher education.

\section{Method}

Description of study. The study sample was drawn from a diverse group ${ }^{53}$ of young people (17 to 22) and their families who were served in SOC initially funded between 2002 and 2005 and who consented to participate in the national evaluation of the CMHI. SOC funded through the CMHI address the needs of children, youth, and families by coordinating community-based services across a variety of child-serving sectors, including mental health, child welfare, juvenile justice, education, and primary care. Key elements of the CMHI include the use of care coordination and cross-agency, familydriven, service planning to ensure that services are coordinated, the service needs of the child or youth are periodically updated, information on progress is provided, financial assistance for services is established, and appropriate services are received. Some grant communities established specific programs or other criteria that offered a specialized focus, or targeted program, for the purpose of meeting selected or specific needs within a community. For example, in some communities services were targeted to very young children or to youth involved in the juvenile justice system. In other communities, services were targeted to specifically serve emerging adults. While few programs specifically focused on emerging adults aged 18 years or older, many more focused on serving youth aged 14-17 years, and nearly all programs incorporated some level of transition services.

A key component of the evaluation is the LCFOS which examines how clinical and functional status and family life change over time for a subset of children/youth between 0 and 22 years of age and their families enrolled in services who agreed to participate in the outcome study. The national evaluation team provided guidance that communities should enroll enough families to ensure a sufficient sample size to detect differences over time in community-specific samples (approximately 110 per year for 3 years). In most communities, all willing families were enrolled in the outcome study. In some communities serving larger populations, the option of developing a sampling strategy based on enrollment rates was available. Longitudinal data were collected from caregivers and youth 11 and older at intake and at subsequent 6-month intervals to assess change over time in a number of domains including behavioral and emotional strengths, social functioning, school attendance and 
performance, stability of living arrangements, and service satisfaction. ${ }^{18}$

Local evaluation staff were responsible for data collection with training and technical assistance provided by national evaluation staff. Local data collection staff included professional research interviewers, college students, family organization staff, members of the community, and service delivery providers. National evaluation staff guided local evaluators to adapt and focus training and support for each type of interviewer. Prior to implementation of data collection, national evaluation staff provided training and guidance on data collection procedures, specifically instructing that those interviewers collecting service satisfaction information should never be under the direct auspices of a service agency or have a role in providing services to consumers. The local evaluation staff were also instructed in the advantages and disadvantages associated with each type of interviewer. The data included in the current study were collected at intake and at 6 and 12 months after intake. Data collection continued through August 2011.

Participants. Data obtained for this study included a sample of 619 young people (ages 17-22) and their families who had agreed to participate in LCFOS and completed data collection interviews at least at intake. Each participant, along with a family member or another caregiver, provided information through interviews gathering information about his or her mental health, education, supportive services, and personal characteristics. Since the research aim was to predict secondary school performance and completion, and engagement in higher education from earlier measures, the study sample was limited to 248 participants who were still enrolled in the longitudinal study at 12 months following intake. The 248 young people who were included in the analysis were not statistically different from the 371 attrited participants in terms of sex, $\chi 2(1, N=619)=.054$, $p=.82$; race, $\chi 2(7, N=619)=11.206, p=.13$; age, $t(573.37, N=619)=-1.51, p=.13$; or Columbia Impairment Scale score, $t(422.96, N=619)=1.37$, $p=.17$. They did, however differ by level of poverty; those who left the longitudinal study were of significantly higher income: $t(381.61, N=619)=$
$-2.14, p=.035$, although the mean family incomes of both groups hovered around the poverty level.

Over half of the young people in the study were male (53.2\%), and lived at (18.0\%) or below (53.5\%) the poverty level. As was expected with young people entering SOC, the average age of the sample was predominantly under $18(M=17.5$ years, $S D$ $=.96$ ) with ages at intake ranging from 17 to 22 . The study sample was racially and ethnically diverse: 30.5\% White, non-Hispanic; 27.6\% Hispanic; 25.2\% Black/African American; 10.2\% American Indian/ Alaska Native; 3.6\% Asian/Native Hawaiian/Pacific Islander; and the remaining $2.8 \%$ multiracial or other race. The majority of participants lived in stable housing at enrollment, with $82.7 \%$ living in their family homes, $11.1 \%$ in therapeutic settings, and the remainder in foster care or in justice settings. These housing arrangements were largely stable through the 12 months, with the majority remaining in their family homes. Most of the young people had education data reported by caregivers (71.0\%), the remainder were interviewed themselves as independent youth (29.0\%). Of the caregivers reporting education information, $74.3 \%$ were biological parents, $7.4 \%$ were adoptive parents or stepparents, $9.1 \%$ were other family members, and the final $3.4 \%$ were staff functioning as caregivers.

The mental health problems reported at enrollment into the study were substantial and serious. Intake interviewers reported that the young people had DSM diagnoses most frequently in the categories of mood disorders (48.8\%), attention deficit/hyperactivity (20.2\%), substance use disorders (14.5\%), oppositional defiant disorders (14.1\%), anxiety disorders (9.3\%), and PTSD (6.9\%). Columbia Impairment Scale (CIS) scores at intake were high $(M=20.91 ; S D=10.08)$, compared to the established clinical cutoff of 15.54

Instruments. The study used sets of measures to collect data addressing four major areas: (a) educational attainments, challenges, and supports, (b) self-reports of emotional and behavioral strengths, including school functioning, (c) self-reports of service experiences, and (d) demographic characteristics of the young people involved in SOC. 
Education measures. The Education Questionnaire-Revised (EQ-R) was completed by parents, other principal caregivers, or youth 18 or older who were living independently. The EQ-R includes 15 major questions with subparts that gather descriptive information on the young person's education including school attendance during the past 6 months, grade level, academic performance, special education services, and disciplinary actions. Although conventional assessments of reliability and validity are not available for these items, the versions of these instruments used in the current study were reviewed and refined by their use in earlier phases of the CMHI evaluation, and have been employed in recent research on education outcomes. ${ }^{55}$

Two major education outcome variables were constructed: school performance, which is a dichotomous variable dividing participants who were in school settings into those whose grades were satisfactory $(1=\mathrm{C}$ average or better in graded settings or satisfactory in ungraded settings) or unsatisfactory ( 0 = below $\mathrm{C}$ average or not satisfactory). Making this variable dichotomous allowed the inclusion of young people who received their education in ungraded settings. The second dichotomous variable higher education engagement divided those who had graduated from secondary school or attained the GED and gone on to higher education (1) from those who had not (0). School attendance was measured by an ordinal item which ranged from (0) "absent from school 3 or more days a week" to (5) "absent less than one day per month."

School functioning. The Behavioral and Emotional Rating Scale-Second Edition, Youth Version (BERS-2Y) was administered to young people ages 11 and older in the LCFOS. BERS-2Y is recognized as a reliable and valid measure of the emotional and behavioral strengths of young people, and has high test-retest reliability overall and for each of the six subscales $(\alpha>.80) .29$ The overall strength index and subscales correlate positively with the Social Skills Rating System, ${ }^{29,56}$ and parent ratings of youth strengths, ${ }^{57}$ and negatively with Achenbach's ${ }^{58}$ Child Behavior Checklist. ${ }^{28,59,60}$ The 9-item School Functioning subscale examines the young person's view of personal accomplishments in school and classroom tasks, for example "I do my schoolwork on time." Items on the School functioning subscale are rated on 4-point scales ranging from (0) "not at all like you" to (3) "very much like you." Scores for all nine items were summed to obtain the BRYS-2Y School Functioning Score, and then converted to standard scores. ${ }^{59}$ The overall strength index and the school functioning scale scores were found to be significantly different for a national sample of youth who had been designated as ED and received special education services when compared to youth without ED. ${ }^{61}$ The BERS-2Y school functioning subscale was highly reliable for young people in the current study with Cronbach's $\alpha=.83$.

Service experiences. The Youth Services Survey (YSS) measures young people's perceptions of their experiences in systems of care. There are five domains of perceptions of services that are constructed from the 21-item scale; the current study uses four of the five domains. Access (two items; not used), participation in treatment (three items), cultural sensitivity (four items), satisfaction (six items) and outcomes in terms of reported functioning in home and school environments (six items). YSS uses a 5-point Likert type scale ( 1 = "Strongly disagree" to $5=$ "Strongly agree") with positively worded items such as "I helped to choose my services" (participation), "Staff were sensitive to my cultural and ethnic background" (cultural sensitivity), "I received services that were right for me" (satisfaction), and "I am better at handling my daily life" (outcomes). The youth version of the instrument is based on the Youth Services Survey-Families, which has an established factor structure of the subscales and high reliability. ${ }^{62}$ Items of the YSS-F were reworded for a version administered to young people that asked them directly about their service experiences. For each subscale, ratings of subscale items were summed, then averaged; subscale scores could range from 1 to 5 . Based on reliability analysis of the State Indicator Pilot Project, ${ }^{63}$ which evaluated data from Colorado, Kentucky, Oklahoma, Texas, Virginia, and the District of Columbia, Cronbach's $\alpha$ for the YSS domain measuring access to services is .71 , participation in treatment is .82 , cultural sensitivity of staff is .90 , satisfaction with 
services is .94, and perceived outcome of services is .86. Similarly, the YSS-F Cronbach's a for the domain measuring access to services is .73, participation in treatment is .77, cultural sensitivity of staff is .91 , satisfaction with services is .94 , and perceived outcome of services is .91 . Scale reliabilities for the youth services subscales in the present study all exceeded Cronbach's $\alpha=.95$.

Demographic measures. The Enrollment and Demographic Information Form (EDIF) was completed at intake and collected information on sex, race, cultural background, family characteristics, agencies involved, presenting problems, and service plans. Additionally, the Living Situations Questionnaire (LSQ) documented the physical setting the youth lived in and whom the young person lived with in the prior 6 months. The LSQ was modified from the Restrictiveness of Living Situations Questionnaire (ROLES) developed by Hawkins et al. ${ }^{64}$ which has proved to be a useful measure in evaluative studies. ${ }^{65,66}$ LSQ data were used to examine the stability of youth living situations.

Data analysis. Results were analyzed using SPSS version 21, and began with a descriptive analysis of key variables, looking for major patterns relating to the research questions. Bivariate analysis permitted exploration of association between key sets of variables. Finally logistic regression analysis was employed to address both research questions by examining demographic items measured at intake, school functioning and service ratings at 6 months, and reports of attendance between 6 and 12 months after intake, as predictors of education outcomes at 12 months.

The regression predicting school performance introduced the demographic variable sex in step 1, adding school attendance and school functioning in step 2, and variables related to services experiences in step 3. This permitted the determination of whether the education-related variables of attendance and self-reported school functioning would add to the prediction of school performance, even after the sex of the participant was taken into account. The regression then examined whether the service experiences of the young person, which are grounded in the context of SOC, added to the prediction of school performance.

The regression predicting higher education engagement began with step 1 introducing demographic variables that have been important predictors of school completion. Step 2 added self ratings of school functioning and service experiences. Finally, step 3 added variables related to school performance and attendance. This logistic regression allowed the determination of the additional capacity of school functioning and service experience variables to predict engagement in higher education, over and above key demographic variables. It also tested whether the addition of school attendance and performance significantly improved prediction of completion of high school and participation in higher education.

\section{Results}

Educational experiences and outcomes. As can be seen in Table 1, a substantial proportion of the 248 young people in SOC were in school at the time of study enrollment $(n=157 ; 63.3 \%)$, and at 12 months nearly half $(n=111 ; 44.8 \%)$ were still engaged in secondary school or higher education. Those who were still engaged in school did not differ significantly from those who left educational settings by sex, race, CIS scores, or poverty level; they were however slightly younger on average $(M$ $=17.18 ; S D=.53)$ than those who remained in school $(M=17.51 ; S D=1.03 ; t[-2.13, N=154.35]$ $=-2.68, p=.008)$. Among those students whose grades were available, the proportion with positive school performance improved from intake (92 of $149 ; 61.7 \%$ with satisfactory grades) to 12 months later ( 87 of $107 ; 81.3 \%$ with satisfactory grades).

Caregivers reported that student school attendance and behavior improved over time as well. At intake $38.1 \%$ of the young people who were in educational settings missed school at least 1 day a week, with $66.7 \%$ of caregivers attributing their poor attendance to emotional or behavioral difficulties. After 12 months in services, only $21.8 \%$ of the young people still in school were absent at least 1 day a week, and only $36.8 \%$ of their caregivers connected 
Table 1. Educational engagement and BERS-2Y scores of young people enrolled in SOC services

\begin{tabular}{lccc}
\hline Educational Status & Enrollment & $\mathbf{6}$ Months & $\mathbf{1 2}$ Months \\
\hline High school diploma/GED \& not in school & $20(8.1 \%)$ & $36(14.5 \%)$ & $57(23.0 \%)$ \\
High school diploma/GED attending college & $3(1.2 \%)$ & $4(1.6 \%)$ & $20(8.1 \%)$ \\
Total high school/GED graduates & $23(9.2 \%)$ & $40(16.1 \%)$ & $77(31 \%)$ \\
\hline In school, grades average C or better & $92(37.1 \%)$ & $77(31.0 \%)$ & $87(35.1 \%)$ \\
In school, grades less than C & $57(23.0 \%)$ & $29(11.7 \%)$ & $4(1.6 \%)$ \\
Grades unknown or missing & $8(3.2 \%)$ & $3(1.2 \%)$ & $111(44.8 \%)$ \\
Total in school & $157(63.3 \%)$ & $109(44.0 \%)$ & $91(36.7 \%)$ \\
\hline Total in high school & $154(62.1 \%)$ & $105(42.3 \%)$ & $80(32.3 \%)$ \\
\hline Not in school, not high school graduate & $54(21.8 \%)$ & $60(24.6 \%)$ & $0(0.0 \%)$ \\
System Missing & $17(6.9 \%)$ & $43(16.9 \%)$ & $8.79(S D=3.30)$ \\
\hline BERS2-Y-Mean School Functioning & $8.34(S D=2.90)$ & $9.04(S D=3.14)$ & $97.18(S D=18.14)$ \\
BERS2-Y-Mean Strength Index & $92.83(S D=16.07)$ & $97.40(S D=16.78)$ & \\
\hline
\end{tabular}

Note. $N=248$; age range 17-22 years. BERS2-Y = Behavioral and

Emotional Rating Scale-Youth (Second Edition); SOC = systems of care.

absences to emotional or behavioral problems. The majority of the young people in school were not receiving special education services (only $38 \%$ at the time of intake, which rose to $44 \%$ after 12 months of services), and even after 12 months of services only $43 \%$ had an Individual Education Plan (IEP).

At the time of enrollment into services, only $23(9.2 \%)$ of the young people had graduated from high school (Table 1); after 12 months, the number of high school graduates in the sample increased to $77(31.0 \%)$. When examined after 12 months of system involvement, rates of high school completion revealed racial/ethnic disparities for these young people $\left(\chi^{2}=13.61, d f=4, p<.009\right)$. High school graduation was less likely for Blacks/African Americans (17.7\%) or Hispanics (20.0\%), than for White Non-Hispanics (41.2\%), American Indian/ Alaska Natives (43.8\%), or young people of other races $(37.5 \%)$.

School performance prediction. Young people were generally positive regarding their strengths as students, given their self-ratings of school functioning and total strength index on the BERS-2Y, as can be seen in Table 1. The total strength index scores are comparable to those obtained by Uhing et al. ${ }^{60}$ in their study which found a mean strength index on the BERS2-Y of 92.27 for a group that was designated as $\mathrm{ED}(S D=14.60)$. At enrollment, school functioning scores differed significantly by $\operatorname{sex}(\mathrm{t}(201)=-2.785, \mathrm{p}<.001)$; females $(M=18.04$; $S D=5.25)$ tended to give higher self-ratings than males $(M=16.02 ; S D=5.10)$.

By the time they had been enrolled in SOC for 6 months, young participants' ratings of their service experiences (seen in Table 2 ) revealed that the youth's average scores were close to 4 = "agree" with positively worded statements. Average participation ratings indicated that they believed they took an active part in their services, and their mean rating of cultural sensitivity of service providers was favorable. They also were generally positive regarding their service satisfaction, and the outcomes of 


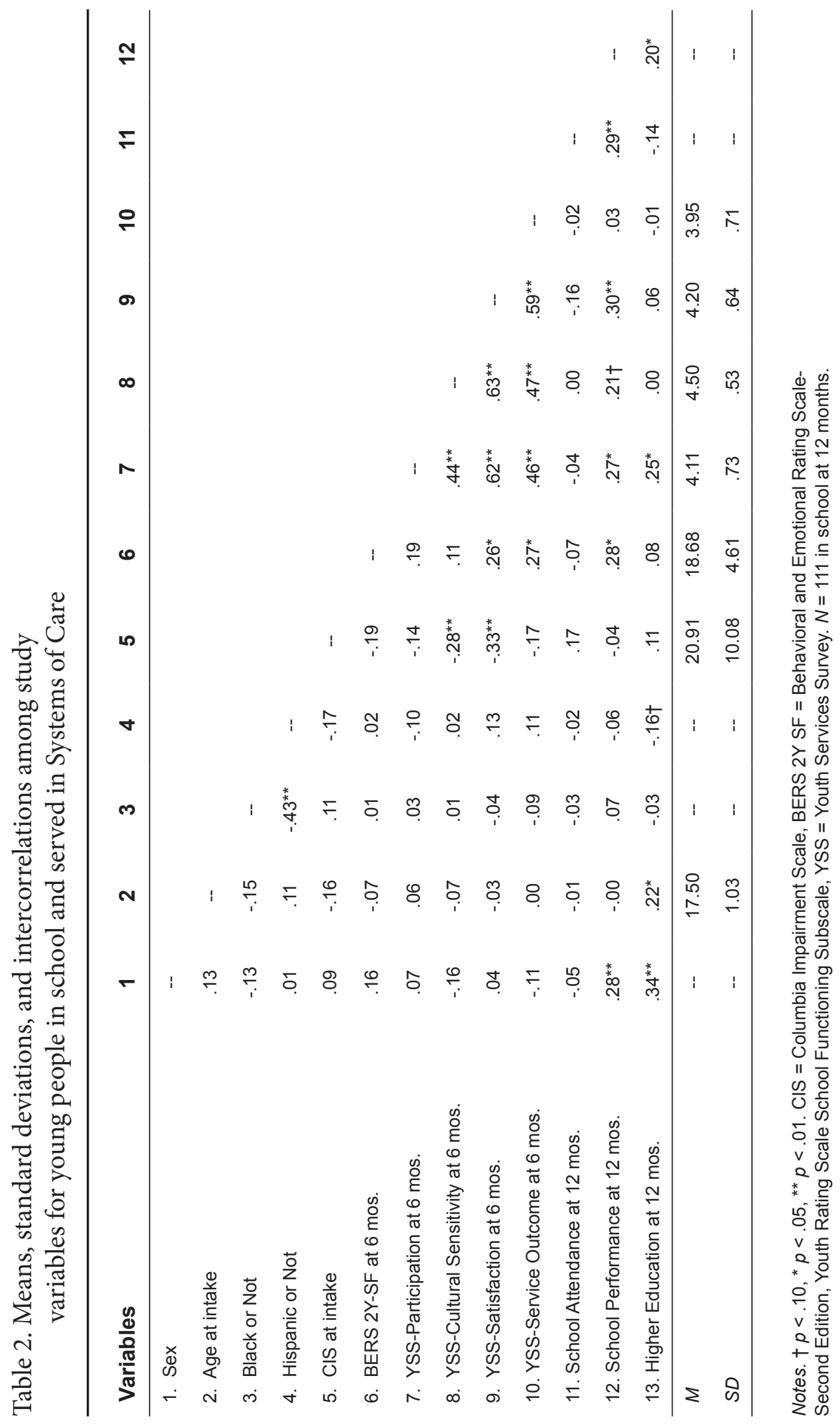

Predicting Positive Education Outcomes for Emerging Adults in Mental Health Systems... 
their services. Bivariate correlations for major study variables appear in Table 2. Of demographic variables, only sex was significantly related to school performance, and level of mental health symptoms was not associated with grades obtained in school. School performance at 12 months was directly correlated with the young people's ratings at 6 months of their school functioning, their participation in services, and their satisfaction with services. There was a trend for those with satisfactory school performance to have rated their services as more culturally sensitive. Service outcome ratings were positively correlated with school functioning ratings given by the young people.

Logistic regression analysis was used to predict school performance for the 111 participants who were engaged in education 12 months after intake, entering in variables on three different steps. As seen in Table 3, the regression determined the relative contributions of sex (step 1), consistency of attendance and self-ratings of school functioning (step 2), and service ratings (step 3) to the prediction of school performance. In step 1, sex significantly predicted school performance, likelihood ratio $\chi^{2}=6.05, d f=1, p<.05$, with Nagelkerke $R^{2}$ $=.113$; females were more likely to have higher levels of school performance than males. When the ratings by young people of their school functioning and reports of school attendance were added in step 2 , the model again significantly predicted school performance, likelihood ratio $\chi^{2}=1.90, d f=$ $3, p<.01$, and there was a significant increase in the prediction, with total Nagelkerke $R^{2}=.230$. Finally, on step 3 the model including all predictor variables (likelihood ratio $\chi^{2}=23.52, d f=7, p=.001$ ) had a substantial total Nagelkerke $R^{2}=.391$. The total set of predictors correctly classified the performance of $87.8 \%$ of the participants.

Engagement in higher education. As can be seen in Table 2, several study variables were significantly related to completion of secondary education and subsequent engagement in higher education for those in school 12 months after enrollment. Demographic variables reflecting sex, age, and race were related to higher education engagement. Higher service participation and school performance measures were also associated with engagement. The results of the logistic regression addressing the second research question are in Table 3. Step 1 introduced sex, race/ethnicity, and age as predictors of educational engagement, with likelihood ratio $\chi^{2}=16.11, d f=4$, $p<.01$; both sex and age made a unique and significant contribution to this prediction. The Nagelkerke $R^{2}=.310$ for Step 1 predictors. In step 2, adding ratings by the young people of their school functioning and service experiences, there was a non-significant increase of the total Nagelkerke $\mathrm{R}^{2}$ to .406 . Finally, on step 3, with the addition of school attendance and school performance measures, there was a significant increase in the prediction of the model, likelihood ratio $\chi^{2}=29.20, d f=10, p=.001$, with total Nagelkerke $\mathrm{R}^{2}=.517$. Sex and attendance independently and significantly predicted engagement in higher education, with females and those with consistent attendance more likely to be enrolled in college. Young people's reports of their level of participation in services at 6 months was also an independent predictor of being in 2 or 4-year colleges at 12 months. The final model correctly predicted outcomes for $86.3 \%$ of the participants.

\section{Discussion}

This study provides evidence that variables related to positive developmental processes can predict favorable education outcomes for young people served in SOC. School performance measures after 12 months of services were positively related to the young people's ratings of their own school functioning, and of their participation in and satisfaction with services. Family members also reported better school attendance and decreased behavioral problems for these young people. Regression results revealed that, even when such strong predictors as sex and school attendance were added into logistic regression equations, the ratings related to self-assessments of functioning and to service experiences, such as level of participation, added to the significant prediction of satisfactory school performance.

As with other studies of young people with emotional or behavioral difficulties, the young people in this sample from the CMHI evaluation had lower rates of completion of high school than their peer 
Table 3. Logistic regressions predicting educational outcomes for young people in Systems of Care Type of Educational Outcome

\begin{tabular}{|c|c|c|c|c|c|c|c|}
\hline \multicolumn{4}{|c|}{ School Performance } & \multicolumn{4}{|c|}{ Higher Education Engagement } \\
\hline Predictor & B & S. E. & OR & Predictor & B & S. E. & OR \\
\hline Step 1 & & & & Step 1 & & & \\
\hline Sex & $1.35^{*}$ & .58 & 3.87 & Sex & $1.91^{*}$ & .75 & 6.78 \\
\hline \multirow[t]{4}{*}{ Nagelkerke $R^{2}$} & .113 & & & Black/African American & .07 & .79 & 1.08 \\
\hline & & & & Hispanic & 1.28 & .84 & 3.59 \\
\hline & & & & Age & $.52^{*}$ & .25 & 1.68 \\
\hline & & & & Nagelkerke $R^{2}$ & .310 & & \\
\hline Step 2 & & & & Step 2 & & & \\
\hline Sex & $1.45^{*}$ & .62 & 4.25 & Sex & $2.10^{*}$ & .85 & 8.20 \\
\hline School Attendance & $.43^{*}$ & .20 & 1.53 & Black/African American & -.21 & .92 & .81 \\
\hline School Functioning & .15 & .11 & 1.77 & Hispanic & .99 & .98 & 2.69 \\
\hline \multirow[t]{6}{*}{ Nagelkerke $R^{2}$} & .230 & & & Age & $.52 \dagger$ & .28 & 1.68 \\
\hline & & & & School Functioning & -.03 & .17 & .97 \\
\hline & & & & Service Participation & $1.53 \dagger$ & .81 & 4.61 \\
\hline & & & & Cultural Sensitivity & -.37 & .99 & .69 \\
\hline & & & & Service Satisfaction & -.27 & 1.02 & .76 \\
\hline & & & & Nagelkerke $R^{2}$ & .406 & & \\
\hline Step 3 & & & & Step 3 & & & \\
\hline Sex & $1.71^{*}$ & .70 & 5.52 & Sex & $2.78^{*}$ & 1.09 & 16.16 \\
\hline School Attendance & $.47^{*}$ & .23 & 1.60 & Black/African American & -.43 & 1.10 & .65 \\
\hline School Functioning & .13 & .13 & 1.13 & Hispanic & 1.19 & 1.07 & 3.23 \\
\hline Service Participation & .78 & .53 & 2.12 & School Functioning & -.05 & .18 & .95 \\
\hline Cultural Sensitivity & 1.21 & .74 & 3.35 & Age & .50 & .31 & 1.65 \\
\hline Service Satisfaction & .76 & .70 & 2.13 & Service Participation & $1.96^{*}$ & 1.01 & 7.07 \\
\hline Service Outcome & $-1.18 \dagger$ & .65 & .31 & Cultural Sensitivity & .10 & .99 & 1.10 \\
\hline \multirow[t]{4}{*}{ Nagelkerke $R^{2}$} & .391 & & & Service Satisfaction & -.65 & 1.05 & .52 \\
\hline & & & & School Attendance & $1.14^{*}$ & .54 & 3.11 \\
\hline & & & & School Performance & -.35 & 1.21 & .70 \\
\hline & & & & Nagelkerke $R^{2}$ & .517 & & \\
\hline
\end{tabular}

Note. $\dagger p<.10,{ }^{*} p<.05 . \quad N=111$ participants in school at 12 months. OR = Odds ratio/Exp(B). 
groups. There also were significant differences by race/ethnicity in high school completion for those who were still in services at 12 months after enrollment. African American and Hispanic youth completed their secondary education at a significantly lower rate than did other racial or ethnic groups, which mirrors the findings of other studies examining school completion and dropout rates. ${ }^{39,40,44}$ It is important to note that although ratings of cultural sensitivity of services were only trending toward being associated with school performance, they were significantly related to the young people's perceptions of their own level of participation and satisfaction with services. These findings are similar to the results of Barksdale et al. ${ }^{67}$ who found that families' ratings of the cultural sensitivity of their services were related to their self-reported participation in services.

On the other hand, in contrast to our findings, a recent study of the educational outcomes of young people in SOC revealed mixed results. Strompolis et al. ${ }^{55}$ examined the outcomes of SOC services in Mecklenburg County, NC, finding that, for the most part, enrollment in services such as special education, case management, and individualized family therapy was not associated with positive changes in grades, suspensions, and absences in children and youth ages $8-16+$. One of the few encouraging associations was found for males in the study who had improved school performance with higher numbers of services and after engagement in family therapy. However, this study did not examine young people's views about their own strengths in educational settings, or their participation in, and satisfaction with, the services they received.

The current study revealed that participation in the planning of their own services was also strongly associated with enrollment in higher education for those who finished high school, even when controlling for such established predictors as sex, age, race, and school performance. Although increased participation in higher education for emerging adults with SMHC may be supported by enlightened educational policies and efforts to combat stigma, ${ }^{68}$ there may also be benefits to having positive experiences with service providers who foster participa- tion in the planning of services, in the selection of goals, and in treatment processes. ${ }^{69,70}$

Study limitations. Study results need to be viewed within the limitations of the study sample. Perhaps most importantly, the original sample of 619 young people and their family members who participated at intake was reduced to a subsample of 248 young people who were still in services 12 months after enrolling in the longitudinal study. This dramatic drop is not surprising, given the precipitous decline in service use during emerging adulthood found by Pottick et al., particularly at age 18.71 The majority of the young people in the current sample were 17 years old at intake, and many left the study before the end of the 12 month period we examined. Our attrition analysis revealed that although major demographic variables did not differ between the participants and those who attrited, those who stayed in the study were from families living in greater poverty. Another important limitation is that data on educational performance and supports were only available at 12 months for those who were participating in school at that time of measurement, due to the design of the Education Questionnaire-Revised (EQ-R). Also, it should be noted that many of the measures being used in this study are based on self-reports by young people of their own strengths and service experiences. Future research might include additional data from school and service records. A final limitation lies in the variety of programs and interventions that are represented in these outcomes. Many, but not all, of the youth included in the sample were served in SOC that targeted emerging adults. ${ }^{72}$ Other youth in the sample were served in systems that targeted broader age ranges. Further, all of the programs serving the youth included in the current sample represent a variety of agencies with multiple portals of entry into services. These agencies employ a multiplicity of approaches to service provision which primarily emphasize reducing and managing behavioral and emotional problems and indirectly impact educational outcomes for this age group. As noted, a hallmark of the CMHI is the support of coordination of services and collaboration of the various agencies involved in providing services. 
Future research. Despite repeated calls for research to build the evidence base on effective practices with young people in transition to adulthood who have serious mental health conditions, ${ }^{73-76}$ there is still a very modest set of studies that address ways in which emerging adults can be supported in the domains of their lives. For example in a study of Check and Connect, a mentoring program serving diverse youth in an urban center, Sinclair et al. ${ }^{50,77,78}$ found that the Check and Connect intervention produced higher rates of consistency in attendance and lower rates of dropout than for young people in the control group. This study, while using a positive development approach, did not include self-reports of young people's perceptions of their own schoolbased strengths or the services they received. The inclusion of such measures might enhance future research.

The findings of the current investigation suggest that researchers who study services designed to improve the education outcomes of young people with SMHC may be well advised to include measures gathering youth reports of their own school functioning. Researchers conducting studies of promising practices and interventions that track youth progress over time could ask young people to rate their own educational strengths as the intervention study progresses, and determine whether targeted supports move those key indicators.

Additionally, approaching research on intervention effectiveness from a positive youth development perspective requires that youth voice be included in these studies, and that young people be asked about their own experiences of services. ${ }^{35,79}$ Studies of services provided to younger people with emotional or behavioral difficulties have been enriched by inclusion of measures that tap into the perceptions of family members regarding service experiences. ${ }^{67,80,81}$ Similarly future studies of emerging adults may be able to develop more powerful models predicting success in their transition to adulthood by including measures that capture young people's experiences regarding key aspects of the services they are offered, such as the cultural sensitivity of the services, and their participation in service planning and choice.

\section{Implications for Behavioral Health}

Young people with mental health challenges who are transitioning out of SOC into adulthood are significantly less likely to perform successfully in secondary school and to go on to higher education than their age cohorts without SMHC. However, there are predictors of positive outcomes for this particular subset of youth that were identified in the current study. Service providers who encourage young people to select their treatment goals, fully participate in services, and make choices that lead to a future they value, may set them on a pathway to seek out and use the services and supports that are available in their education settings and across other domains in their lives. When young people with serious mental health conditions have support across the domains of their lives, there is increased hope for recovery and successful participation in education and the workforce. ${ }^{82}$ Further, when mentors or service providers recognize and voice the youth's strengths and accomplishments, the young person may be more engaged in services and regard them positively. Similarly, if service providers are youth directed, listen to and act on the youth's needs, engage youth in treatment planning, and offer culturally responsive support, youth of color and other disadvantaged or marginalized young people may experience higher participation in services, greater satisfaction with services, better service outcomes, and better school performance. Consistent with Woolsey and Katz-Levy, ${ }^{83}$ the present findings suggest that service providers can benefit from using a process that successfully identifies individual strengths as "the stepping stone" to attainment of education, career, and life goals. As greater numbers of behavioral health service programs aimed at emerging adults are implemented, ${ }^{84}$ increasing attention to the use of positive youth development approaches seems appropriate. As these data suggest, when young people are encouraged to believe in themselves and work toward a desired future their functioning and outcomes in educational settings may improve.

\section{Conflict of Interest}

The authors have no conflicts of interest to report. 


\section{Acknowledgments}

This research was supported through the Research and Training Center for Pathways to Positive Futures by the National Institute of Disability and Rehabilitation Research, United States Department of Education, and the Center for Mental Health Services Substance Abuse and Mental Health Services Administration, United States Department of Health and Human Services (NIDRR grants H133B090019 and H133B140039). The authors acknowledge the assistance of the Data Access Group of ICF International and the Center for Mental Health Services. The manuscript is based on data from the National Evaluation of the Comprehensive Community Mental Health Services for Children and their Families Program. The authors are grateful for the reviews of this manuscript provided by Jason Newsom and Corinne Bacharach Spiegel.

Disclaimers. The views expressed in the article are those of the authors and do not necessarily reflect the official policies of the United States Department of Health and Human Services, or does the mention of trade names, commercial practices, or organizations imply endorsement by the U. S. Government.

\section{References}

1. Pew Research Center. Young, Underemployed and Optimistic: Coming of Age, Slowly, in a Tough Economy. Social and Demographic Trends. Pew Research Trends, Washington DC. Available online at http://www.pewsocialtrends.org/2012/02/09/ young-underemployed-and-optimistic/. Accessed January 1, 2014.

2. Oreopoulos P, Salvanes K. Priceless: The nonpecuniary benefits of schooling. Journal of Economic Literature, 2011; 25(1): 159-184.

3. Schmidt KL, Phelps E, Lerner RM. Constructing positive futures: Modeling the relationship between adolescents' hopeful future expectations and intentional self regulation in predicting positive youth development. Journal of Adolescence, 2011; 34(6): 1127-1135.

4. Schwartz SJ, Côté JE, Arnett JJ. Identity and agency in emerging adulthood: Two developmental routes in the individualization process. Youth \& Society, 2005; 37: 201-229.
5. Cargo M, Grams GD, Ottoson JM, et al. Empowerment as fostering positive youth development and citizenship. American Journal of Health Behavior, 2003; 27(Supplement 1): S66-S79.

6. Catalano RF, Berglund ML, Ryan JAM., et al. Positive youth development in the United States: Research findings on evaluations of positive youth development programs. The Annals of the American Academy of Political and Social Science, 2004; 591: 98-124.

7. Kia-Keating M, Dowdy E, Morgan ML, et al. Protecting and promoting: An integrative conceptual model for healthy development of adolescents. Journal of Adolescent Health, 2011; 48: 220-228.

8. Lerner RM, Lerner JV, Lewin-Bizan S, et al. Positive youth development: Processes, programs, and problematics. Journal of Youth Development: Bridging Research and Practice, 2011; 6(3): 41-64.

9. Walker J, Gowen K, Jivanjee P, et al. Pathways to Positive Futures: State-of-the-Science Conference Proceedings (Part 1). Portland, OR: Portland State University, Research and Training Center for Pathways to Positive Futures, 2013.

10. Stein KF. Experiences of selected emerging adults with emotional or behavioral difficulties in higher education. Career Development and Transition for Exceptional Individuals, 2012; 35(3): 168-179.

11. Newman L, Wagner M, Knokey A, et al. The Posthigh School Outcomes of Young Adults with Disabilities Up to 8 years after High School: A Report from the National Longitudinal Transition Study-2 (NLTS2). Menlo Park, CA: SRI International, 2011.

12. Wagner M, Newman L. Longitudinal transition outcomes of youth with emotional disturbances. Psychiatric Rehabilitation Journal, 2012; 35(3): 199-208.

13. Wagner M, Newman L, Cameto R, et al. After High School: A First Look at the Post-school Experiences of Youth with Disabilities. A report from the National Longitudinal Transition Study-2 (NLTS2). Menlo Park, CA: SRI International, 2005.

14. Moses T. Being treated differently: Stigma experiences with family, peers, and school staff among adolescents with mental health disorders. Social Science and Medicine, 2010; 70(7): 985-993.

15. Walker JS, Coleman D, Lee J. Children's stigmatization of childhood depression and ADHD: Magnitude and demographic variation in a national 
sample. Journal of the American Academy of Child and Adolescent Psychiatry, 2008; 47(8): 912-920.

16. Burke-Miller JK, Cook JA, Grey, DD, et al. Demographic characteristics and employment among people with severe mental illness in a multisite study. Community Mental Health Journal, 2006; 42(2): 143-159.

17. Naicker K, Galambos NL, Zeng Y, et al. Social, demographic, and health outcomes in the 10 years following adolescent depression. Journal of Adolescent Health, 2013; 52(5): 533-538.

18. Holden EW, Friedman RM, Santiago RL. Overview of the National Evaluation of the Comprehensive Community Mental Health Services for Children and their Families program. Journal of Emotional and Behavioral Disorders, 2001; 9: 4-12.

19. Manteuffel B, Stephens RL, Brashears F, et al. Evaluation results and systems of care: A review. In: BA Stroul, GB Blau (Eds.). The System of Care Handbook. Baltimore, MD: Paul H. Brookes, 2008, pp. 25-69.

20. Zigmond N. Twenty-four months after high school: Paths taken by youth diagnosed with severe emotional and behavioral disorders. Journal of Emotional and Behavioral Disorders, 2006; 14: 99-107.

21. Manteuffel B, Stephens RL, Sondheimer DL, et al. Characteristics, service experiences, and outcomes of transition-aged youth in systems of care: Programmatic and policy implications. The Journal of Behavioral Health Services \& Research, 2008; 35: 469-487.

22. Bradley R, Doolittle J, Bartolotta, R. Building on the data and adding to the discussion: The experiences and outcomes of students with emotional disturbance. Journal of Behavioral Education, 2008; 17: 4-23.

23. Doll JJ, Eslami Z, Walters L. Understanding why students drop out of high school, according to their own reports: Are they pushed or pulled, or do they fall out? A comparative analysis of seven nationally representative studies. Sage Open, 2013; 3. Available online at http://sgo.sagepub.com/content/3/4/2158244013503834.full-text.pdf+html. Accessed January 1, 2014.

24. Rumberger RW, Thomas SL. The distribution of dropout and turnover rates among urban and suburban high schools. Sociology of Education, 2000; 73: 39-67.
25. Schoeneberger, J. Longitudinal attendance patterns: Developing high school dropouts. The Clearing House, 2012; 85: 7-14.

26. Smith-Osborne, A. Antecedents to postsecondary educational attainment for individuals with psychiatric disorders: A meta-analysis. Best Practices in Mental Health, 2005; 1(1): 15-30.

27. Diseth $\AA$, Danielsen AG, Samdal O. A path analysis of basic need support, self-efficacy, achievement goals, life satisfaction and academic achievement level among secondary school students. Educational Psychology: An International Journal of Experimental Educational Psychology, 2012; 32(2): 335-354.

28. Green J, Liem GAD, Martin AJ, et al. Academic motivation, self-concept, engagement, and performance in high school: Key processes from a longitudinal perspective. Journal of Adolescence, 2012; 35(5): 1111-1122.

29. Epstein MH, Mooney P, Ryser G, et al. Validity and reliability of the Behavioral and Emotional Rating Scale (2nd Edition): Youth Rating Scale. Research on Social Work Practice, 2004; 14(5): 358-367.

30. Furlong MJ, Sharkey JD, Boman P, et al. Crossvalidation of the Behavioral and Emotional Rating Scale-2 Youth Version: An exploration of strengthbased latent traits. Journal of Child and Family Studies, 2007; 16(5): 696-711.

31. Anderson JA. Patterns of school functioning over time among students served in a system of care. Remedial and Special Education 2011; 32(6): 482-495.

32. Brown JD, Riley AW, Walrath CM, et al. Academic achievement and school functioning among nonincarcerated youth involved with the juvenile justice system. Journal of Education for Students Placed at Risk, 2008; 13(1): 59-75.

33. Davis M. Addressing the needs of youth in transition to adulthood. Administration and Policy in Mental Health, 2003; 30(6): 495-509.

34. Stroul BA, Blau GM, Sondheimer DL. Systems of care: A strategy to transform children's mental health care. In: BA Stroul, GB Blau (Eds.). The System of Care Handbook. Baltimore, MD: Paul H. Brookes, 2008, pp. 3-23.

35. Carter EW, Trainor A, Owens L, et al. Self-determination prospects of youth with high-incidence disabilities: Divergent perspectives and related factors. Journal of Emotional and Behavioral Disorders, 2010; 18: 67-81. 
36. Field SS, Martin JE, Miller RJ, et al. Self-determination for persons with disabilities: A position statement of the Division on Career Development and Transition. Career Development for Exceptional Individuals, 1998; 21: 113-128.

37. Pierson MR, Carter EW, Lane KL, et al. Factors influencing the self-determination of transitionage youth with high incidence disabilities. Career Development for Exceptional Individuals, 2008; 31: 115-125.

38. Stillwell, R. Public School Graduates and Dropouts from the Common Core of Data: School Year, 2006-07. U.S. Department of Education, National Center for Education Statistics, Publication NCES 2010-313. Available online at http://nces.ed.gov/ pubsearch/ pubsinfo.asp?pubid=2010313. Accessed January 1, 2014.

39. Bauman GL, Bustillos LT, Bensimon EM, et al. Achieving Equitable Educational Outcomes with All Students: The Institution's Roles and Responsibilities. Making Excellence Inclusive Series. Washington, DC: Association of American Colleges and Universities, 2005.

40. Kao G, Thompson JS. Racial and ethnic stratification in educational achievement and attainment. Annual Review of Sociology, 2003; 29: 417-442.

41. Cross T, Bartgis J, Fox K. Rethinking the systems of care definition: An indigenous perspective. Evaluation and Program Planning, 2010; 33: 28-31.

42. Serpell ZN, Clauss-Ehlers CS, Weist MD. Next steps: Advancing culturally competent school mental health. In: CS Clauss-Ehlers, ZN Serpell, MD Weist. (Eds.). Handbook of Culturally Responsive School Mental Health: Advancing Research, Training, Practice, and Policy. New York, NY: Springer, 2013, pp. 251-260.

43. Banks J. Barriers and supports to postsecondary transition: Case studies of African American students with disabilities. Remedial and Special Education, 2014; 35(1): 28-39.

44. Bradley CL, Renzulli LA. The complexity of noncompletion: Being pushed or pulled to drop out of high school. Social Forces, 2011; 90(2): 521-545.

45. Stephens RL, Xu Y, Gyamfi P. Racial and ethnic differences in caregivers' ratings on the cultural competence of their service providers in systems of care. In: C Newman, C Liberton, K Kutash, et al. (Eds.). 20th Annual Research Conference
Proceedings: A System of Care for Children's Mental Health: Expanding the Research Base. Tampa: University of South Florida, Louis de la Parte Florida Mental Health Institute, Research and Training Center for Children's Mental Health, 2008, pp. 224-227.

46. Ungar M, Liebenberg L, Dudding P, et al. Patterns of service use, individual and contextual risk factors, and resilience among adolescents using multiple psychosocial services. Child Abuse \& Neglect, 2013; 37(2): 150-159.

47. Gleason P, Dynarski M. Do we know whom to serve? Issues in using risk factors to identify dropouts. Journal of Education for Students Placed at Risk, 2002; 7(1): 25-41.

48. Rumberger RW. Why Students Drop Out of School and What Can Be Done. Paper presented at the Harvard University Conference, Dropouts in America: How Severe is the Problem? What Do We Know about Intervention and Prevention? Cambridge, MA, January, 2001.

49. Scanlon D, Mellard, DF. Academic and participation profiles of school-age dropouts with and without disabilities. Exceptional Children, 2002; 68(2): 239-258.

50. Sinclair MF, Christenson SL, Thurlow ML. Promoting school completion of urban secondary youth with emotional or behavioral disabilities. Exceptional Children, 2005; 71(4): 465-482.

51. Armstrong KH, Dedrick RF, Greenbaum PE. Factors associated with community adjustment of young adults with serious emotional disturbance: A longitudinal analysis. Journal of Emotional and Behavioral Disorders, 2003; 11: 66-76.

52. Montague M, Enders C, Cavendish W, et al. Academic and behavioral trajectories for at-risk adolescents in urban schools. Behavior Disorders, 2011; 36(2): 141-156.

53. Meich R, Goldstein AB, Azur M, et al. The potential to reduce mental health disparities through the comprehensive community mental health services for children and their families. Journal of Behavioral Health Services \& Research, 2008; 35(3): 253-264.

54. Bird HR, Shaffer D, Fisher P, et al. The Columbia Impairment Scale (CIS): Pilot findings on a measure of global impairment for children and adolescents. International Journal of Methods in Psychiatric Research, 1993; 3: 167-176. 
55. Strompolis M, Vishnevsky T, Reeve CL, et al. Educational outcomes in a system of care for children with emotional disturbance. American Journal of Orthopsychiatry, 2012; 82(1): 129-136.

56. Gresham FM, Elliott SN. Social Skills Rating System Manual. Circle Pines, MN: American Guidance Service, 1990.

57. Synhorst LL, Buckley JA, Reid R, et al. Cross informant agreement of the Behavioral and Emotional Rating Scale-2nd Edition (BERS-2) parent and youth rating scales. Child \& Family Behavior Therapy, 2005; 27(3): 1-11.

58. Achenbach TM. Manual for the Youth Self Report and 1991 Profile. Burlington: University of Vermont, Department of Psychiatry, 1991.

59. Buckley J, Ryser G, Reid R, et al. Confirmatory factor analysis of the Behavioral and Emotional Rating Scale-2 (BERS-2) Parent and Youth Rating Scales. Journal of Child and Family Studies, 2006; 15(1): 27-37.

60. Mooney P, Epstein MH, Ryser G, et al. Reliability and validity of the Behavioral and Emotional Rating Scale-Second Edition: Parent Rating Scale. Children \& Schools, 2005; 27: 147-155.

61. Uhing BM, Mooney P, Ryser GR. Differences in strength assessment scores for youth with and without ED across the youth and parent rating scales of the BERS-2. Journal of Emotional and Behavioral Disorders, 2005; 13(3): 181-187.

62. Riley SE, Stromberg AJ, Clark J. Assessing parent satisfaction with children's mental health services with the Youth Services Survey for Families. Journal of Child and Family Studies, 2005; 14(1): 87-99.

63. Brunk M, Koch JR, McCall, B. Report on Parent Satisfaction with Services at Community Services Boards. Richmond, VA: Virginia Department of Mental Health, Mental Retardation, and Substance Abuse Services, 2000.

64. Hawkins RP, Almeida MC, Fabry B, et al. A scale to measure restrictiveness of living environments for troubled children and youths. Hospital and Community Psychiatry, 1992; 43(1): 54-58.

65. Thomlison B. Restrictiveness as a measure to monitor children's placements at the program and case level. In: C Liberton, K Kutash, R Friedman (Eds.). A System of Care for Children's Mental Health: Expanding the Research Base 5th Annual Research
Conference Proceedings. Tampa, FL: University of South Florida, Florida Mental Health Institute, Research and Training Center for Children's Mental Health, 1991, pp. 97-104.

66. Yoe JT, Bruns E, Burchard J. Evaluating individualized services in Vermont: Behavioral and service outcomes. In: C Liberton, K Kutash, R Friedman (Eds.). A System of Care for Children's Mental Health: Expanding the Research Base 7th Annual Research Conference Proceedings. Tampa, FL: University of South Florida, Florida Mental Health Institute, Research and Training Center for Children's Mental Health, 1994, pp. 9-14.

67. Barksdale CL, Ottley PG, Stephens R, et al. Systemlevel change in cultural and linguistic competence (CLC): How changes in CLC are related to service experience in systems of care. American Journal of Community Psychology, 2012; 49: 483-493.

68. Ellison ML, Rogers ES, Costa A. Supporting the educational goals of young adults with psychiatric disabilities. In: M Davis (Ed.). Tools for System Transformation for Young Adults with Psychiatric Disabilities: State of the Science Papers. Worcester, MA: University of Massachusetts Medical School, Department of Psychiatry, Center for Mental Health Services Research, Transitions RTC, 2013, pp. 1-20.

69. Clark HB, Unruh DK. Transition of Youth and Young Adults with Emotional or Behavioral Difficulties: An Evidence-based Handbook. Baltimore, MD: Paul H. Brookes

70. Walker JS, Pullmann MD, Moser CL, et al. Does team-based planning "work" for adolescents? Findings from studies of wraparound. Psychiatric Rehabilitation Journal, 2012; 35(3): 189-198.

71. Pottick KJ, Bilder S, Vander Stoep A, et al. US patterns of mental health service utilization for transition-age youth and young adults. The Journal of Behavioral Health Services \& Research, 2007; 35(4), 373-389.

72. Carter EW, Lane KL, Crnobori M, et al. Self-determination interventions for students with and at risk for emotional and behavioral disorders: Mapping the knowledge base. Behavioral Disorders, 2011; 36(2): 100-116.

73. Clark HB, Koroloff N, Geller J, et al. Research on transition to adulthood: Building the evidence base to inform services and supports for youth and 
young adults with serious mental health disorders. Journal of Behavioral Health Services \& Research, 2008; 35(4): 365-372.

74. Gilmer TP, Ojeda VD, Fawley-King K. Change in mental health service use after offering youthspecific versus adult programs to transition-aged youth. Psychiatric Services, 2012; 63(6): 592-596.

75. Lane KL, Carter EW. Supporting transition-age youth with and at risk for emotional and behavioral disorders at the secondary level: A need for further inquiry. Journal of Emotional and Behavioral Disorders, 2006; 14: 66-70.

76. Wagner M, Davis, M. How are we preparing students with emotional disturbances for the transition to young adulthood? Journal of Emotional and Behavioral Disorders, 2006; 14(2), 86-98.

77. Sinclair M, Christenson S, Evelo D, et al. Dropout prevention for youth with disabilities: Efficacy of a sustained school engagement procedure. Exceptional Children, 1998; 65, 7-21.

78. Sinclair MF, Christenson SL, Lehr CA, et al. Facilitating student engagement: Lessons learned from Check \& Connect longitudinal studies. The California School Psychologist, 2003; 8 (1): 29-42.

79. Fleming J. Young people's involvement in research: Still a long way to go? Qualitative Social Work, 2010; 10(2): 207-223.
80. Gyamfi P, Lichtenstein C, Fluke J, et al. The relationship between child welfare involvement and mental health outcomes of young children and their caregivers receiving services in System of Care communities. Journal of Emotional and Behavioral Disorders, 2012; 20(4): 211-225.

81. Pullman MD. Participatory research in systems of care for children's mental health. American Journal of Community Psychology, 2009; 44 (1-2): 43-53.

82. Jivanjee P, Kruzich J, Gordon LJ. Community integration of transition-aged individuals: Views of young adults with mental health disorders. The Journal of Behavioral Health Services \& Research, 2008; 35: 402-418.

83. Woolsey L, Katz-Levy J. Transitioning Youth with Mental Health Needs to Meaningful Employment and Independent Living. Washington, DC: National Collaborative on Workforce and Disability for Youth, Institute for Educational Leadership, 2008.

84. Davis M. Pioneering Transition Programs: The Establishment of Programs that Span the Ages Served by Child and Adult Mental Health. Rockville, MD: Substance Abuse and Mental Health Services Administration, Center for Mental Health Services, 2007.

This manuscript was published online March 25, 2015 in the Journal of Behavioral Health Services \& Research. The final publication is available at Springer via http://link.springer.com/article/10.1007/s11414-015-9454-y

This activity is supported by a grant funded by both the National Institute of Disability, Independent Living, and Rehabilitation Research, and the Center for Mental Health Services Substance Abuse and Mental Health Services Administration, United States Department of Health and Human Services (NIDILRR grant 90RT5030). NIDILRR is a Center within the Administration for Community Living (ACL). The content does not necessarily represent the policy of NIDILRR, ACL, HHS, and you should not assume endorsement by the Federal Government.

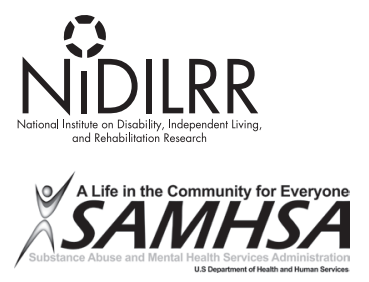

